\title{
0 que é desenvolvimento regional? Uma aproximação a partir da realidade brasileira
}

\author{
Ivo Marcos Theis \\ Universidade Regional de Blumenau - Blumenau - Santa Catarina - Brasil
}

\begin{abstract}
Resumo
compreensão um pouco mais contextualizada do que possa ser desenvolvimento regional. De forma que se buscará, nos limites de um artigo breve e objetivo, definir o contexto no qual se possa formular uma noção mais precisa de desenvolvimento regional. A preocupação não é com a elaboração de um conceito abstrato; ela está na tessitura de um quadro, que tem ganho nitidez na pós-graduação brasileira nas três últimas décadas, no qual se possa formular uma compreensão de desenvolvimento regional que corresponda à realidade sociocultural brasileira. Ao pretender-se contribuir para a construção do quadro referido, no qual se pode avançar um entendimento mais preciso de desenvolvimento regional, define-se o Brasil como lócus privilegiado desta tentativa, e suas características socioculturais (como o idioma, a institucionalidade educacional etc.) como referências inamovíveis. Por fim, o artigo sugere que as exigências para que se reconheça o desenvolvimento regional como um campo de conhecimento autônomo estão atendidas.
\end{abstract}

Palavras-chave: Brasil. Desenvolvimento Regional. Área de conhecimento.

\section{What ist regional development? An approach since the brazilian sociocultural reality}

\begin{abstract}
This article focuses on regional development issues. The main purpose is to offer a somewhat more contextualized understanding of what regional development might be. Thus, within the limites of a brief and objective article, the context within which a more precise notion of regional development can be formulated will be sought. The concern is not with the elaboration of an abstract concept; it is with the frame of a picture that has gained sharpness in Brazilian graduate studies in the last three decades, in which an understanding of regional development that corresponds to the Brazilian sociocultural reality can be formulated. In order to contribute to the construction of the aforementioned framework, in which a more precise understanding of regional development can be advanced, Brazil is defined as the privileged locus of this attempt, and its sociocultural characteristics (such as language, educational institutions etc.) as immovable references. Finally, the article suggests that the requirements for the recognition of regional development as an autonomous field of knowledge are met.
\end{abstract}

Keywords: Brazil. Regional Development. Field of knowledge. 


\section{Qué es desarrollo regional? Una aproximación desde la realidad sociocultural brasileña}

\section{Resumen}

Este artículo se dedica a la problemática del desarrollo regional. El propósito es ofrecer una comprensión un poco más contextualizada de lo que pueda ser desarrollo regional. De modo que se buscará, dentro de los límites de un artículo breve y objetivo, definir el contexto en el que se pueda formular una noción más precisa de desarrollo regional. La preocupación no es que se elabore un concepto abstracto; ella está en la tesitura de un quadro que há ganado nitidez en el postgrado brasileño en las tres últimas décadas, en el que se pueda formular una comprensión de desarrollo regional que corresponda a la realidade sociocultural brasileña. Al pretender contribuir a la construcción del marco referido, en el que se puede avanzar un entendimiento más preciso de desarrollo regional, se define a Brasil como locus privilegiado de este intento, y sus características socioculturales (como el idioma, la institucionalidad educativa etc.) como referencias inamovibles. Por último, el artículo sugere que las exigencias para que se reconozca el desarrollo regional como un campo de conocimiento autónomo están atendidas.

Palabras clave: Brasil. Desarrollo Regional. Campo de conocimiento.

"Regionalmente deve ser estudada, sem sacrifício do sentido de sua unidade, a cultura
brasileira, do mesmo modo que a natureza; o homem da mesma forma que a paisagem.
Regionalmente devem ser considerados os problemas de economia nacional e os de
trabalho"
(Gilberto Freyre, 2010, p. 71)

\section{Introdução}

Este artigo é consagrado à problemática do desenvolvimento regional. Problemática é um termo que, aqui, se refere a algo que desperta/requer atenção e, por isso, demanda algum tipo de solução. Mas, o que, de fato, se procura fazer nas páginas a seguir é oferecer uma compreensão um pouco mais contextualizada do que seja, ou possa ser, desenvolvimento regional. Se bem tenha havido sucessivas tentativas de precisar melhor o que se pode entender por desenvolvimento regional, elas podem ser consideradas malsucedidas. É evidente que nada assegura que precisamente esta tentativa experimente sorte maior. Entretanto, em contraposição aos louváveis esforços realizados até o presente, procurar-se-á, nos limites de um artigo breve e tão objetivo quanto possível, definir minimamente o contexto no qual se possa formular uma noção mais precisa de desenvolvimento regional. Assim, a preocupação maior deverá ser com o quadro no qual se pode elaborar uma compreensão de desenvolvimento regional.

Uma advertência importante: a preocupação de se oferecer um entendimento um pouco mais contextualizado de desenvolvimento regional precisa, ela mesma, ser contextualizada. Isto é, cabe informar devidamente em qual âmbito tal preocupação emerge e ganha sentido. Concretamente: o contexto é dado pelo subcampo do desenvolvimento regional, da área de Planejamento Urbano e Regional, que, como estabelece a CAPES, integra as chamadas Ciências Sociais Aplicadas. Portanto, sem excluir ex ante quaisquer outros interlocutores interessados ou afetos à 
problemática, procura-se, com este artigo, dialogar com aquelas e aqueles que militam - isto é, ensinam, orientam e pesquisam - nesta subárea da avaliação da pósgraduação brasileira. Que não haja dúvidas, pois, que, a despeito de simpatias e mesmo de afinidades com a produção intelectual que tem lugar fora da academia, mira-se uma interlocução, sobretudo, com aquelas e aqueles que se encontram vinculados a programas de pós-graduação em desenvolvimento regional. Ainda a respeito do âmbito: referir à CAPES e à pós-graduação brasileira significa limitar a problemática à realidade sociocultural brasileira1. Não se trata nem de desprezar o que vai fora das fronteiras nacionais nem de recear o enfrentamento do tema em um contexto internacional mais amplo. Se a preocupação é de contribuir para a construção do quadro acima referido, no qual se pode elaborar uma compreensão mais precisa de desenvolvimento regional, então se define o Brasil como lócus privilegiado e suas características socioculturais (como o idioma, a institucionalidade educacional etc.) como referências inamovíveis.

O artigo está dividido em sete seções principais, a primeira delas sendo esta introdução. O passo-a-passo que deve conduzir a uma compreensão mais precisa de desenvolvimento regional deverá começar pelo esboço de um breve panorama internacional. Destina-se alguma atenção à problemática do desenvolvimento regional fora do Brasil? O que se entende por desenvolvimento regional em outros países? A seção seguinte já avança em direção à perspectiva brasileira, elegendo como referência a obra de Celso Furtado. Como o economista paraibano identificou e analisou a problemática regional brasileira? Terá ela influenciado estudos mais recentes de/sobre desenvolvimento regional? Em seguida, procura-se examinar a questão regional a partir da produção intelectual que vem tendo lugar na universidade brasileira, em especial, nos programas de pós-graduação [PPG], mas também nos grupos de pesquisa e na atuação dos próprios pesquisadores. Afinal, que lugar tem aí desenvolvimento regional? Uma seção quase complementar é dedicada aos periódicos científicos que deveriam ser portadores, por assim dizer, da produção intelectual em/sobre desenvolvimento regional. Como se caracteriza e quão representativa é o conjunto de revistas especializadas em desenvolvimento regional nas quais deságua a produção brasileira? A penúltima seção, talvez, a mais importante, é consagrada à formulação de uma proposição. Ela envolve três passos prévios, que, então, conduzem à identificação de três enfoques de desenvolvimento regional. Por fim, uma última seção é destinada às chamadas "considerações finais", em que não apenas se faz a habitual síntese do artigo, mas também se especula sobre as possibilidades de o desenvolvimento regional vir a atender as exigências de um campo de conhecimento autônomo.

\footnotetext{
1 Realidade que, evidentemente, é condicionada pelas condições materiais próprias ao modo de produção dominante (o capitalismo), no contexto de uma formação social periférica e dependente em relação às formações sociais que vêm coordenando/comandando a economia-mundo.
} 


\section{Breve panorama internacional}

Não obstante se pretenda definir minimamente o contexto no qual se possa elaborar uma noção mais precisa de desenvolvimento regional a partir de uma aproximação desde a realidade brasileira, parece conveniente tomar em consideração o que, a propósito, se entende por desenvolvimento regional fora do Brasil.

É desnecessário que se faça um esforço sobrehumano para verificar que a expressão desenvolvimento regional tem tradução em diversas línguas conhecidas. Com efeito, nos journals especializados, publicados em inglês, encontra-se, sem dificuldades, a expressão regional development. Nos periódicos especializados publicados em língua alemã é, igualmente, frequente a expressão Regionalentwicklung. Também nos periódicos especializados publicados em língua francesa é comum a expressão développement régional. Assim, evidentemente, também nos periódicos especializados publicados em espanhol ocorre a expressão desarrollo regional.

Assumindo-se, pois, que desenvolvimento regional tem tradução em vários idiomas, cabe perguntar o que se quer dizer com essa expressão em cada idioma e, principalmente, se o seu significado é, por assim dizer, convergente nas diversas línguas. A resposta está dificultada por vários motivos, entre eles: a) uma mesma língua (por exemplo, o inglês) pode ser compartilhada por diferentes países (por exemplo, EEUU e Índia), mas o seu uso em cada um deles pode levar a que palavras iguais (por exemplo, região) assumam diferentes significados; b) mesmo no interior de um país (por exemplo, Inglaterra) podem existir diferentes "correntes de pensamento" (por exemplo, "escolas de desenvolvimento regional"), para as quais termos (por exemplo, região) e expressões (por exemplo, desenvolvimento regional) iguais tendem a carregar valores próprios; c) como acontece com outras expressões, os significados de desenvolvimento regional, em diferentes línguas, podem modificar-se ao longo do tempo. De forma que se pode responder à questão formulada no início deste parágrafo apenas se se abstraírem as dificuldades referidas (entre diversas outras não mencionadas). Isto posto, e com base em fontes selecionadas ao acaso, que cobrem artigos científicos e livros, publicados ao longo dos últimos 50 anos, proceder-se-á a uma "verificação" do que pode significar desenvolvimento regional nas línguas conhecidas já mencionadas.

Algumas observações preliminares com relação à origem dos textos: a) dos oito, há sempre dois em cada um dos quatro idiomas (isto é, dois em inglês, dois em alemão, dois em francês e dois em espanhol); b) seis deles encontram-se em formato de artigo científico, enquanto dois são, de fato, livros; c) dois foram publicados na presente década, quatro na década dos anos 2000 e dois no século passado (um nos anos 1960 e outro nos anos 1980); d) os autores dos oito textos são de distintas nacionalidades. Apesar de, como informado acima, as fontes terem sido selecionadas ao acaso, o propósito nesta seção é examinar, brevemente, um conjunto de materiais que exploram a problemática do desenvolvimento regional em outros contextos socioculturais.

Dentre os textos aqui considerados, o de Casey J. Dawkins, professor da Universidade de Maryland, é por assim dizer o de maior fôlego. Trata-se de um "estado da arte", que oferece tanto uma abrangente revisão do campo do 
desenvolvimento regional quanto, também, uma "bibliografia anotada" da literatura teórica mais representativa. A compilação de Dawkins (2003) cobre materiais orundos de diversas disciplinas, com destaque para a economia (mainstream, digase) - que acaba sobrassaindo - e a geografia. Os temas em torno dos quais Dawkins (2003) elabora seu texto são: (a) as previsões teóricas referentes à convergência de renda per capita ao longo do tempo, (b) os pressupostos quanto à relevância das economias de escala para o desenvolvimento econômico, e (c) o papel do espaço na determinação dos mercados de trabalho em escala regional.

Um artigo mais recente, assinado por Frank Moulaert, Bob Jessop e Abid Mehmood, e publicado em International Journal of Urban Sciences, aborda o desenvolvimento regional da perspectiva de um instrumental que combina ação (agency), estrutura (structure), instituições (institutions) e discurso (discourse) - o que resulta no modelo ASID. O propósito revelado por Moulaert et al. (2016) é de, na análise de processos de desenvolvimento socioeconômico, obter significados relevantes em termos de suas dinâmicas espaço-tempo. Concretamente, o modelo ASID busca ligar teorias de médio alcance com a realidade empírica a partir de oito eixos de pesquisa, incluindo: ação econômica estratégica em desenvolvimento local, regulação jurídico-política em escala nacional e regional, organização socioeconômica local-regional etc.

O segundo mais antigo texto, publicado há mais de três decênios num importante periódico da geografia alemã, é de autoria de Martin Coy, atualmente, professor do Instituto de Geografia da Universidade de Innsbruck (Áustria). Debruçando-se sobre o desenvolvimento regional do Estado de Rondônia, no Norte brasileiro, Coy (1986) procurou examinar as implicações sociais, econômicas e políticas de programas de desenvolvimento regional, em especial, o Polonoroeste. Ao considerar que o modelo de desenvolvimento modernizante então vigente no Brasil produzia disparidades espaciais, Coy (1986), identificava a expressão desenvolvimento regional com programas governamentais (que criticava) e, potencialmente, com um planejamento orientado para o combate das desigualdades e da pobreza em espaços periféricos (caso de Rondônia).

Outro artigo em língua alemã é de autoria de Sabine Mühlinghaus. Ele foi publicado no início dos anos 2000 em Geographica Helvetica, conhecida revista da geografia suíça. O tema que recebe a atenção de Mühlinghaus (2002) já se encontra explicitado no título, ou seja, um desenvolvimento regional autônomo como estratégia para espaços rurais periféricos. Constatando que o processo de globalização aparecia, sobretudo, para espaços periféricos (a exemplo das regiões montanhosas da Suíça) como ameaça para a manutenção de postos de trabalho principalmente, na agricultura e na produção manufatureira voltadas para o mercado doméstico - Mühlinghaus (2002) identificava desenvolvimento regional com estratégias baseadas em maior independência e autonomia das comunidades regionais.

O mais antigo dos textos é de autoria de J. C. Perrin (professor da Faculdade de Direito e de Ciências Econômicas, em Aix en Provence), tendo sido publicado no periódico francês Cahiers Orstom (Sci. Hum.) na segunda metade dos anos 1960. Relativamente longo, ele pode ser considerado um pequeno livro, já que alcança quase 60 páginas. Dividido em duas seções principais, na primeira delas examinamse assim chamados 'esquemas de crescimento econômico' e 'o modelo regional'. Na 
segunda seção são passadas em revista as estruturas de crescimento e organização regional em 'países em vias de desenvolvimento'. O autor consagra a conclusão às 'possibilidades' de desenvolvimento regional. De qualquer forma, o que neste texto de Perrin (1967) logo fica evidente é uma preocupação maior, senão exclusiva, com aspectos econômicos.

Outro texto publicado em francês é da lavra de Amor Belhedi. Ele integra um livro - cujo título é La fracture territorial - que ganhou a superfície nesta década. $O$ tema é o desenvolvimento regional numa perspectiva mais ampla, como já antecipa o seu subtítulo: problemáticas, objetivos e princípios. De fato, Belhedi (2012) explicita suas posições ao informar que desenvolvimento não se limita a prover uma dada população de bens materiais e econômicos. Pelo contrário, é preciso considerar o seu caráter de totalidade, de um todo indissociável, assim permitindo que o conceito inclua preocupações como: a redução de desigualdades territoriais, a promoção de justiça social e espacial, e a busca da dignidade como sua finalidade última. De maneira que Belhedi (2012) assume que desenvolvimento regional é uma questão de natureza política.

Dos dois textos publicados em espanhol, o primeiro é assinado por três pesquisadores vinculados ao Instituto Tecnológico de Oaxaca. O artigo em questão, que trata das desigualdades identificadas entre as grandes regiões do México, foi publicado numa importante revista daquele país, Problemas del Desarrolo. Considerando um período relativamente longo, de 1950 a 2003, Velasco et al. (2007) utilizam um sofisticado instrumental metodológico para mensurar a eficiência, a equidade e a sustentabilidade do desenvolvimento regional no México. Suas conclusões são de que a eficiência pode ser observada em grande parte do período, mas não a equidade nem a sustentabilidade. Na verdade, a preocupação com a questão ambiental é recente e as desigualdades regionais têm se agravado entre meados do século passado e o início do atual.

O ultimo dos textos aqui examinados é de autoria de Victor Ramiro Fernández, investigador argentino, vinculado à Universidad Nacional del Litoral, publicado em EURE, um dos mais prestigiosos periódicos sobre questões urbanas e regionais editados na América Latina. O tema são as possíveis estratégias de desenvolvimento regional, dado o então novo cenário da globalização - na realidade, Fernández (2001) emprega o termo glocalization. Passando em revista diversos enfoques regionalistas e confrontando-os com dados empíricos (que mostravam o agravamento das assimetrias inter e intra-regionais), Fernández (2001) colocaria em questão o otimismo daqueles que viam êxitos certos nas estratégias usuais de mobilização endógena de recursos - que desconsideravam a escala nacional - para promover o desenvolvimento regional.

O que, afinal, se entende por desenvolvimento regional "fora” do Brasil? Em apertada síntese, e considerando apenas os textos acima sumariados, podem-se identificar preocupações relativas a desigualdades sócio-espaciais, relações de poder, aspectos éticos e até questões metodológicas. Contudo, a dimensão econômica é a que predomina, por exemplo, em Dawkins (2003) e Perrin (1967), embora na maioria dos demais textos ela também se manifeste, pelo menos, implicitamente. De forma que, fora do Brasil, desenvolvimento regional pode ser reconhecido, fundamentalmente, como um processo econômico. 
Visto, brevemente, o que se entende por desenvolvimento regional com o auxílio de textos publicados em outros países, pode-se voltar a atenção agora para a realidade sociocultural brasileira, associando-se a noção de desenvolvimento regional, inicialmente, à obra de um de seus mais representativos intelectuais.

\section{Desenvolvimento regional na perspectiva de Celso Furtado}

Grande parte da produção intelectual brasileira sobre desenvolvimento regional no período recente (isto é, nas últimas três a quatro décadas) faz referência, direta ou indiretamente, à obra de Celso Furtado (BERCOVICI, 2003; CANO, 1998 [1981]; DINIZ, 2009; OLIVEIRA, 1981; TAVARES, 2011). É, sem lugar à dúvida, uma razão suficiente para não se ignorar a sua importante contribuição. Por isso, nesta seção sumariam-se e se comentam algumas publicações do economista paraibano em que a problemática do desenvolvimento regional emerge de forma mais destacada.

A mais importante obra de Celso Furtado - reconhecido clássico da história econômica do Brasil - indica não apenas que o tema deveria merecer atenção, mas também que a questão regional deveria ser adequadamente contextualizada. Por exemplo, ao referir-se à relevância do café na conformação territorial da economia brasileira, afirma:

o desenvolvimento da primeira metade do século XX apresenta-se como um processo de articulação das distintas regiões do país em um sistema com um mínimo de integração. O rápido crescimento da economia cafeeira - durante o meio século compreendido entre 1880 e 1930 - se por um lado criou fortes discrepâncias regionais de renda per capita, por outro dotou o Brasil de um sólido núcleo em torno ao qual as demais regiões tiveram necessariamente de articular-se [...] a região rio-grandense [...] foi a primeira a beneficiar-se da expansão do mercado interno induzido pelo desenvolvimento cafeeiro [...] A articulação com a região nordestina se faz por intermédio da própria economia açucareira [...] Por último a Amazônia se incluiu entre os beneficiários da grande expansão da região cafeeiraindustrial (FURTADO, 1977, p. 237).

Pouco adiante, indicará como o processo de industrialização - conquanto favoreça a constituição do mercado interno por intermédio da 'articulação das distintas regiões do país em um sistema com um mínimo de integração' - concorrerá para o aumento das disparidades entre as regiões, à base da concentração de terras naquelas em que se vai verificar uma perda de importância da agricultura de subsistência:

Da perspectiva do território brasileiro, os espaços nos quais as terras permanecem mais concentradas são aqueles do Norte/Nordeste, nos quais diminuiu a relevância das lavouras tradicionais. Será essa dinâmica, impulsionada a partir dos anos 1930 pela industrialização, que alimentará não apenas as desigualdades sociais que se perpetuam no país, mas também as disparidades inter-regionais (FURTADO, 1977, p. 237-238).

Em “perspectivas da economia brasileira” (publicado em 1958), Celso Furtado procede a uma divisão em dois sistemas econômicos principais para identificar 'problemas de disparidade regional' no território brasileiro. Note-se que ele os 
associa ao desenvolvimento (industrial) orientado pela ação dos agentes privados no mercado, em consequência do que as desigualdades se vieram esgarçando no tempo:

\begin{abstract}
Seria grave equívoco supor que esses problemas de disparidade regional se resolverão espontaneamente e que por isso não devem constituir preocupação central da política geral de desenvolvimento. Tudo indica que nos últimos 15 anos [...] as disparidades regionais se acentuaram. 0 desenvolvimento está contribuindo, portanto, para agravar essas disparidades e não para resolvê-las (FURTADO, 2012 [1958], p. 61).
\end{abstract}

Ao aí conferir centralidade à problemática regional, Celso Furtado convida a enfrentar as referidas disparidades, inscrevendo-a em um programa nacional de desenvolvimento: "As políticas regionais de desenvolvimento pressupõem uma compreensão dos objetivos nacionais de desenvolvimento" (FURTADO, 2012 [1958], p. 64).

Nos anos 1960, num trabalho menos citado, o economista paraibano chegou a diagnosticar (e a propor estratégias para enfrentar) o que então chamou de 'descontinuidades subnacionais'. Diagnóstico e política, porém, se encaixavam em ousado esboço de 'teoria sobre estruturas espaciais', em que inferia serem os diversos critérios derivados da análise setorial e regional uma questão de decisão política (FURTADO, 1967).

Mais tarde, no início dos anos 1980, sobretudo, em "o Brasil pós-milagre”, a questão regional ganharia sofisticação na sua preocupação com o Nordeste. Para dela tratar, volta a distinguir o território brasileiro em dois espaços distintos, reiterando sua preocupação com as disparidades regionais, agravadas no período em que o país acelerara a sua industrialização:

Os problemas mais difíceis que nos afligem na fase atual, quando completamos um século de esforços pelos caminhos da industrialização, refletem de uma ou outra forma essa rachadura criada pelas dissimetrias entre as duas regiões que são as matrizes de nossa nacionalidade (FURTADO, 1981, p. 120).

No entanto, na sequência, Celso Furtado elabora um argumento que permitiria explicar a 'rachadura' diagnosticada: “Queiramos ou não, os grandes problemas do Brasil somente podem ser diagnosticados se se tem do país uma visão que leve em conta a fratura fundamental dessa desigualdade regional" (FURTADO, 1981, p. 120).

Seu argumento partirá, pois, da construção de 'uma visão que leve em conta a fratura' verificada no território. Tal visão não poderia cingir-se a considerar a regiãoproblema, o Nordeste, dissociada da região na qual as forças produtivas se encontram mais desenvolvidas, o Centro-Sul. E que influência esta vinha exercendo sobre a região-problema? A resposta, na época, bastante original, era de que o Nordeste se tornara espaço de industrialização complementar à região mais desenvolvida:

As relações estruturais que vieram a prevalecer fazem que a industrialização nordestina seja, no essencial, uma prolongação do 
desenvolvimento industrial do Centro-Sul, e só secundariamente uma resposta aos requerimentos da população local (FURTADO, 1981, p. 122).

Pouco mais adiante, o argumento vai se completando. A realidade configurada pela 'rachadura', captada por uma visão ampla das assimetrias referidas, se explica pela necessidade do capital (acumulado na região mais desenvolvida) se expandir. A sua expansão implica, simultaneamente, uma desorganização das atividades tradicionais e a organização de atividades novas, mobilizadoras dos recursos agora disponíveis ${ }^{2}$, com vistas não ao atendimento de demandas concretas da população nordestina, mas à produção do que é definido desde a região mais desenvolvida:

\begin{abstract}
ao transformar-se num espaço em que se localizam atividades industriais complementares da economia do Centro-Sul, o mercado de bens de consumo nordestino teve de adaptar-se à estrutura da oferta de produtos industriais que se origina na região de maior desenvolvimento relativo. $\mathrm{A}$ nova dependência reside exatamente na subordinação à lógica de uma industrialização que abarca o conjunto do país e é comandada do CentroSul, transformando-se o Nordeste em simples apêndice de um mercado dominado por uma clientela de nível de renda mais alto e onde se exacerbam as tendências consumistas (FURTADO, 1981, p 123-124).
\end{abstract}

Se, em escala nacional, a industrialização definida desde a região mais desenvolvida gerava desigualdades sociais e espaciais, a sua expansão em direção à região-problema tendia não somente a ampliar as distâncias entre os dois sistemas econômicos principais, como a gerar disparidades (sociais e intra-regionais) ainda maiores no Nordeste, na medida em que as decisões fundamentais tinham origem no Centro-Sul do país:

o quadro estrutural das relações inter-regionais que emergiu da industrialização recente opera no sentido de aprofundar a dependência do Nordeste: o mercado da região é cada vez mais um complemento do mercado do Centro-Sul e os investimentos industriais que aí se realizam subordinam-se à lógica da economia do Centro-Sul; destarte, as malformações do desenvolvimento desta última aparecem ampliadas na região mais pobre (FURTADO, 1981, p. 125).

O argumento furtadiano não apenas se valeria de dados empíricos que o comprovavam cabalmente, mas também repousava em uma interlocução com outras dimensões que, com elegância rara entre economistas, o completavam. Com efeito, poucas páginas adiante, faria comparecer elementos - não-econômicos - que moldariam o quadro no qual contextualizaria seu argumento, com especial destaque para a cultura e a história, afirmando, por exemplo, que: "A identidade do brasileiro tem raízes em sua inserção regional, reflete um sistema de valores que cristalizou, a partir de elementos comuns ou não, em cada sub-região do imenso território do qual

\footnotetext{
2 De fato, aí afirma: “como ignorar que [a] 'ajuda' à industrialização levou à destruição de múltiplas atividades produtivas locais e inibiu a criação de outras, pois tendeu a tudo subordinar à lógica da integração com o Centro-Sul”? (FURTADO, 1981, p. 130).
} 
se assenhorou a Coroa portuguesa" (FURTADO, 1981, p. 138). E, logo em seguida, assinalando um dos traços mais relevantes da formação do Brasil, observaria que: "O problema inicial era [...] o da fragilidade dos vínculos entre grupos de população espalhados em um vasto território, quase sempre articulados de forma autônoma a centros econômicos no exterior" (FURTADO, 1981, p. 139).

É certo que, com o tempo, neste vasto território, as diferentes regiões acabariam por articular-se umas com as outras, produzindo-se uma coesão interna mínima. Qual seria, porém, a alternativa a um desenvolvimento que se fundava na dependência das diversas regiões em relação a centros econômicos mais dinâmicos, que desconhecia identidades e valores, impondo sua lógica quase que inexoravelmente a todos os espaços que lhe são periféricos? Novamente, a resposta do economista paraibano surpreende por recorrer a elementos não-econômicos, afirmando que "O desenvolvimento do Nordeste terá que ser inventado na própria região a partir de sua realidade ecológica e do patrimônio cultural que cimenta a identidade dos nordestinos" (FURTADO, 1981, p. 152).

A "questão regional" ainda receberia atenção de Celso Furtado, como no capítulo sétimo - "O Nordeste: novo modelo de desenvolvimento?" - de livro que publicaria pouco depois (FURTADO, 1982b). Contudo, ele retomaria o assunto, inclusive, recuperando a visão ampla com que já o havia abordado, em um breve, mas penetrante exame do federalismo brasileiro, observando:

\begin{abstract}
Como somos um país com fronteiras que se deslocam permanentemente dentro do próprio território, nosso conceito de região é necessariamente dinâmico. Mas essa consciência de unidade nacional, dentro de um espaço que se expande, coexiste com o senso de identidade que se definiu historicamente em cada região particular. A identidade do brasileiro tem raízes em sua inserção regional... (FURTADO, 1999, p. 47).
\end{abstract}

Aí, como se percebe, explicitaria a sua preocupação com o desenvolvimento regional, contrastando a 'consciência da unidade nacional' - que, não por acaso, se afirmava com o centralismo que caracterizaria o primeiro governo Vargas ${ }^{3}-$ com o $^{\circ}$ sentimento de identidade regional. Neste período, em que se desencadearia no país "o verdadeiro processo de industrialização" (FURTADO, 1982a, p. 20), induzido pelo Estado e, por isso, mais autônomo em comparação com o que ocorrera anteriormente, articular-se-iam as regiões brasileiras entre si, constituindo, finalmente, uma unidade econômica com vinculações e complementaridades outrora inexistentes. Assim: "Sem desconhecer os aspectos negativos das desigualdades regionais que se agravavam, não se pode ignorar que nessa época [anos 1930] foi forjada uma sólida interdependência inter-regional” (FURTADO, 1999, p. 51). Mais adiante, ler-se-ia que "a industrialização apoiada no mercado interno deu origem a vínculos profundos entre regiões que antes mantinham entre si escassas relações econômicas" (idem, p. 52).

\footnotetext{
3 “A consolidação do poder central, que se esboça em 1930 e se confirma em 1937, dota o país de um centro de decisões com considerável autonomia vis-à-vis dos grupos econômicos tradicionais. Caem as barreiras aduaneiras entre estados e tomam-se muitas outras medidas visando a unificar o mercado nacional..." (FURTADO, 1982a, p. 22).
} 
Ao meditar sobre como evoluiu o federalismo brasileiro, o economista paraibano parte de seu diagnóstico das disparidades regionais para propor uma alternativa política, ajustada à institucionalidade político-administrativa então vigente, sugerindo que:

não seria fora de propósito discutir a possibilidade de uma esfera regional de poder. A fórmula a ser encontrada deveria preservar os estados atuais e, mediante a inserção do poder regional, buscar corrigir os aspectos mais negativos das desigualdades demográficas e territoriais existentes (FURTADO, 1999, p. 55).

Reconhecendo que o processo de centralização promovido pelos governos militares se tenha exacerbado, ultrapassando os limites de governabilidade de regiões tão diversas em aspectos (tanto socioeconômicos e políticos quanto também culturais e ecológicos) essenciais, Celso Furtado recomendaria que a transferência de poder às instâncias locais e regionais se baseasse numa cuidadosa estratégia de planificação, de molde a contemplar os interesses e as necessidades identificáveis no território. Em suas palavras: "A descentralização regional do poder central deveria ser acompanhada de um planejamento plurianual que permitisse compatibilizar as aspirações das distintas regiões" (FURTADO, 1999, p. 56).

Que balanço se poderia fazer da contribuição de Celso Furtado para a questão regional no Brasil? Em apertada síntese, e considerando somente as publicações acima selecionadas (notando-se que entre a primeira e a última há um intervalo de 40 anos), pode-se reconhecer uma análise perspicaz da lógica econômica que tem governado o desenvolvimento brasileiro e suas repercussões sobre o território. Não obstante se manifestasse sobre economia como economista (que considerava um cientista social), examinou a problemática regional brasileira considerando suas inúmeras implicações. Se, porém, fosse preciso resumir o diagnóstico furtadiano, poder-se-ia vaticinar que ele desvendou a natureza do processo de desenvolvimento desigual que preside a economia brasileira, uma economia subdesenvolvida porque periférica; e se fosse preciso resumir a estratégia furtadiana para enfrentar o desenvolvimento regional desigual, poder-se-ia sopesar que, desde uma visão global, ele privilegiou a política, em seu sentido mais nobre, como meio de desmontar os mecanismos que têm perpetuado e, mesmo, agudizado as disparidades interregionais no Brasil.

\section{Desenvolvimento regional na universidade brasileira}

Há, evidentemente, uma produção intelectual sobre desenvolvimento regional na universidade brasileira que tem origem em outras fontes. Talvez não seja despropositado indicar a influência que exerceram, entre outros, Gunnar Myrdal (1957), François Perroux (1950, 1955) e Albert O. Hirschman (1958) no debate sobre desenvolvimento regional a partir de meados dos anos 1950/início dos anos 1960. Mas, parece fora de dúvida que, nas últimas três a quatro décadas, tenha sido com a obra de Celso Furtado que, direta ou indiretamente, a produção intelectual oriunda da academia tenha estabelecido uma interlocução mais profícua para tratar da problemática regional no Brasil. O legado do economista paraibano tem sido uma referência importante para um número não desprezível de especialistas, entre eles, 
Otamar de Carvalho (2014), Pedro Bandeira (1999, 2007) e Liana Maria da Frota Carleial (1993, 2014).

Convém assinalar que, sobretudo, nos dois últimos decênios, uma larga parcela da produção intelectual sobre desenvolvimento regional na universidade brasileira vem tendo seu espaço privilegiado na pós-graduação. A agência que regula esta importante atividade ligada à educação superior do país é a Coordenação de Aperfeiçoamento de Pessoal de Nível Superior [CAPES]. Ela se ocupa de acompanhar a pós-graduação brasileira através de avaliações frequentes, classificando os diversos programas de pós-graduação [PPG] por critérios de qualidade. Os PPG encontram-se vinculados a 49 grandes áreas que, por sua vez, se distribuem por três grandes "colégios" (Colégio de Ciências da Vida, Colégio de Ciências Exatas, Tecnológicas e Multidisciplinar, e Colégio de Humanidades). Poder-se-ia identificar "desenvolvimento regional" em PPG em diversas dessas 49 grandes áreas - por exemplo, enquanto linha de pesquisa e/ou área de concentração em algum PPG da grande área Geografia. Poder-se-ia identificar "desenvolvimento regional”, também, em algum PPG da grande área Interdisciplinar. Interessam aqui, porém, os PPG ligados à grande área "Planejamento Urbano e Regional/Demografia".

Para proceder a uma aproximação dos PPG de desenvolvimento regional, convém, antes, caracterizar, minimamente, a grande área "Planejamento Urbano e Regional/Demografia". O primeiro dos PPG dessa grande área surgiu em Porto Alegre, na Universidade Federal do Rio Grande do Sul [UFRGS], em 1970. Dois anos depois, portanto, em 1972, foi criado o segundo PPG dessa grande área no Rio de Janeiro, na Universidade Federal do Rio de Janeiro [UFRJ] - ambos os PPG em "planejamento urbano e regional". Desde então vem aumentando consideravelmente o número de PPG nesta grande área. Entretanto, um crescimento mais acentuado se daria nos anos 2000 - tanto na área "Planejamento Urbano e Regional/Demografia” como em toda a pós-graduação brasileira (CIRANI et al., 2015).

Após a avaliação quadrienal 2013-2016, realizada no segundo semestre de 2017, contam-se 48 PPG na grande área "Planejamento Urbano e Regional/Demografia"4 - um número extraordinário, se se lembrar que em princípios dos anos 1970 havia apenas dois PPG de/em "planejamento urbano e regional" no Brasil. Desses 48 PPG, quatro eram da área de "Demografia". Portanto, a área de Planejamento Urbano e Regional, propriamente, somava 44 PPG. Desses, nove eram Mestrados Profissionais, dois eram Doutorados (acadêmicos) ligados a Mestrados Profissionais e 33 eram PPG acadêmicos.

O "campo" (ou: a subárea) do "Desenvolvimento Regional”, propriamente, abarcava 18 PPG acadêmicos e três Mestrados Profissionais. Isso equivalia a algo como 54\% do total dos PPG acadêmicos e 33\% dos Mestrados Profissionais da área de “Planejamento Urbano e Regional”; ou, considerando a grande área, 37\% e 30\%, respectivamente. Cabe lembrar que a história dos PPG desta subárea principia bem mais tarde. Com efeito, o primeiro PPG de Desenvolvimento Regional surgiu apenas em 1994, na Universidade de Santa Cruz do Sul [UNISC], localizado no município de Santa Cruz do Sul, do Estado do Rio Grande do Sul. O segundo PPG de

\footnotetext{
${ }^{4}$ No momento em que se fazia a última revisão do texto (12 de junho de 2019), o número de PPG na grande área em questão chegava a 50. Para os fins aqui propostos, contudo, considerar-se-ão os dados da última avaliação quadrienal da CAPES.
} 
Desenvolvimento Regional surgiu no ano 2000, na Universidade Regional de Blumenau [FURB], no município de Blumenau, do Estado de Santa Catarina. O terceiro surgiu no ano de 2003, na Universidade Estadual do Oeste do Paraná [UNIOESTE], no município de Toledo, do Estado do Paraná.

Aqui cabe destacar que os três primeiros PPG do "campo" (ou: da subárea) do Desenvolvimento Regional tiveram origem em Instituições de Ensino Superior não-privadas, mas também não-federais, localizadas em "municípios do interior" (isto é, não capitais), em “cidades médias” (isto é, não em grandes centros urbanos) dos três estados do Sul do Brasil - região reconhecida por diversas iniciativas, algumas pioneiras, baseadas no associativismo - num período de menos de 10 anos, entre a primeira metade dos anos 1990 e a primeira metade dos anos 2000. Trata-se, vale lembrar, de um momento em que a globalização neoliberal avançava sobre os países periféricos. No Brasil, passaram a ser adotadas medidas econômicas que teriam forte repercussão sobre o tecido social. A política econômica liberal então posta em marcha, baseada em elevadas taxas de juros, na privatização de empresas públicas e na abertura comercial, conduziu a uma reestruturação produtiva sem precedentes. Em consequência, aumentou o desemprego e caíram os rendimentos do trabalho. Portanto, pode-se afirmar, sem maior receio, que a criação dos primeiros PPG em Desenvolvimento Regional, entre princípios dos anos 1990 e o início dos anos 2000, constituiu uma resposta, encontrada na Região Sul, à globalização neoliberal que, então, já produzia seus graves efeitos econômicos e sociais no Brasil.

Talvez o surgimento dos demais 18 PPG desta subárea (inclusive, os três mestrados profissionais), que, evidentemente, se deu na sequência, também repouse nas mesmas motivações. No entanto, é provável que a principal responsável pela abertura dos novos PPG no "campo" do Desenvolvimento Regional seja a “interiorização” da pós-graduação brasileira. De fato, salvo exceções, os novos PPG em Desenvolvimento Regional foram criados em IES relativamente mais jovens, localizadas, em sua maioria, mais longe da imensa faixa litorânea ao longo da qual, historicamente, emergiram as mais antigas IES brasileiras.

É aí, pois, nos PPG de IES mais jovens do "interior" do Brasil, que vem tendo lugar uma interessante produção intelectual sobre desenvolvimento regional. Esta tem sido animada por fontes diversas, algumas já referidas. Contudo, parece inegável que, nos últimos três a quatro decênios, venha sendo, sobretudo, a obra de Celso Furtado que tem inspirado, direta ou indiretamente, a produção intelectual dessa banda mais nova da academia no tratamento da problemática regional brasileira. Há uma óbvia vantagem nisso: o desenvolvimento regional no Brasil vem sendo, cada vez mais, objeto de pesquisa das/nas próprias regiões brasileiras.

Considere-se a possibilidade de identificar a pesquisa em desenvolvimento regional, isto é, os grupos de pesquisa e os/as pesquisadores/as que se dedicam ao tema. O que há? $\mathrm{E}$, sobretudo, qual é relação entre 'pesquisa' em desenvolvimento regional e 'pós-graduação' em desenvolvimento regional?

Tabela 1. Grupos de Pesquisa em Desenvolvimento Regional, 2016

\begin{tabular}{c|c|c}
\hline Área de conhecimento & $\begin{array}{c}\text { Grupos de } \\
\text { Pesquisa }\end{array}$ & $\begin{array}{c}\% \text { em } \\
\text { relação ao total }\end{array}$ \\
\hline Grande Área de Sociais Aplicadas & 5.363 & 14,3 \\
\hline
\end{tabular}




\begin{tabular}{c|c|c}
\hline Área de Planejamento Urbano e Regional & 233 & 0,6 \\
\hline Subárea de Desenvolvimento Regional (a) & 608 & 1,6 \\
\hline Subárea de Desenvolvimento Regional (b) & 408 & 1,1 \\
\hline Subárea de Desenvolvimento Regional (c) & 121 & 0,3 \\
\hline Total & 37.640 & 100 \\
\hline
\end{tabular}

Fonte: $\mathrm{CNPq}$ < http://lattes.cnpq.br/web/dgp > Acesso: 03.02.2018

(a) Busca realizada combinando os campos "Nome do grupo", "Nome da linha de pesquisa" e "Palavra-chave da linha de pesquisa"; (b) busca realizada combinando os campos "Nome do grupo" e "Nome da linha de pesquisa"; (c) busca limitada ao campo "Nome do grupo".

Os dados do último Censo realizado pelo CNPq informavam que existiam mais de 37 mil grupos de pesquisa no Brasil5. A tabela acima permite verificar a importância relativa dos grupos de pesquisa que se dedicavam à problemática do desenvolvimento regional - apareça esta expressão como palavra-chave, como linha de pesquisa e/ou mesmo designe o grupo. Grupos de pesquisa que tinham desenvolvimento regional no nome eram pouco mais de 230 - o que equivale a somente $0,6 \%$ do total de grupos de pesquisa existentes no país. Este número parece demasiadamente modesto. Mas, a título de comparação, o número de grupos de pesquisa que tinham "desenvolvimento local" no nome eram apenas 29 , o dos que tinham "desenvolvimento territorial sustentável” no nome eram só cinco. Não há espaço, aqui, para se aprofundar a relação entre grupos de pesquisa e pósgraduação, de forma que esta questão sugere investigação futura.

Quanto aos pesquisadores que se dedicam ao tema, os dados mais precisos são os gerados pelo Portal da Inovação [http://www.portalinovacao.mct.gov.br/pi/\#/pi] - aliás, este sendo alimentado por dados provenientes da Plataforma Lattes do CNPq. Por intermédio de um ranking, o Portal da Inovação permite identificar os pesquisadores segundo suas respectivas "competências", informando, por exemplo, a instituição em que eles atuam profissionalmente. $O$ que acontece quando se pede a palavra-chave "desenvolvimento regional" nas competências? A lista dos 10 primeiros traz cinco pesquisadores sobre desenvolvimento regional que atuam como docentes em PPG da subárea de desenvolvimento regional; dos 10 seguintes, o número de pesquisadores sobre desenvolvimento regional que atuam como docentes em PPG da subárea chega a sete; somados, tem-se então 12 pesquisadores, entre 20 , sobre desenvolvimento regional que atuam como docentes em PPG da subárea de desenvolvimento regional, ou seja, $60 \%$. Isso parece revelar que, da perspectiva do/a investigador/a, a disseminação do tema "desenvolvimento regional" é impulsionada pela atuação de pesquisadores-docentes em PPG da subárea de desenvolvimento regional. De qualquer maneira, também esta questão sugere investigação futura.

Até aqui a atenção foi orientada para a pós-graduação como espaço privilegiado de larga parcela da produção intelectual sobre desenvolvimento regional na universidade brasileira, sobretudo, nas duas últimas décadas. Mas, e a graduação? Dificilmente, poder-se-ia examinar nesta breve intervenção a relevância da temática do desenvolvimento regional em cursos de graduação oferecidos por IES brasileiras. A razão é simples: inexistiam, no Brasil, cursos de graduação em desenvolvimento

\footnotetext{
${ }^{5}$ No momento em que se fazia a última revisão do texto (12 de junho de 2019), o número de grupos de pesquisa recenseado pelo CNPq permanecia inalterado.
} 
regional até pouco tempo atrás. Quanto à presença do tema "desenvolvimento regional" em outros cursos de graduação existentes, um levantamento aqui seria despropositado - embora deva ser registrado que em diversas IES brasileiras ele esteja presente. É o caso do Centro Universitário para o Desenvolvimento do Alto Vale do Itajaí [UNIDAVI], com sede no município de Rio do Sul, no Estado de Santa Catarina, que oferece um curso de graduação em "Ciências Econômicas e Desenvolvimento Regional”. Todavia, agora já existem cursos de graduação em desenvolvimento regional. No segundo semestre de 2014 iniciou a primeira turma do Bacharelado Interdisciplinar em Ciência e Tecnologia [BICT], oferecido pela UFRGS em seu Campus Litoral Norte, no município de Tramandaí, no estado do Rio Grande do Sul. O BICT/UFRGS do Campus Litoral Norte prevê quatro "terminalidades": Licenciatura em Geografia, Bacharelado em Engenharia de Gestão de Energia, Bacharelado em Engenharia de Serviços e Bacharelado em Desenvolvimento Regional. O BICT compreende um ciclo comum aos quatro cursos que dura três [3] anos e outro que dura dois [2] anos, correspondendo ao específico de cada curso, à "terminalidade"

[https://www.ufrgs.br/campuslitoralnorte/ensino/desenvolvimento-regional acesso em 0402 2018].

Que balanço se poderia fazer da contribuição da universidade brasileira para a questão regional no Brasil? Em primeiro lugar, pode-se notar que essa contribuição existe e tem se tornado cada vez mais importante; em segundo, a crescente relevância da universidade brasileira para a problemática regional pode ser atribuída, principalmente, à pós-graduação; em terceiro, também é certo que grupos de pesquisa e investigadores, em grande medida, ligados a PPG da subárea, são responsáveis por parcela considerável da produção intelectual em desenvolvimento regional; em quarto lugar, a temática do desenvolvimento regional também já alcançou a graduação, embora aí a sua presença seja quase imperceptível. O desafio que, então, se apresenta é o da qualidade dessa contribuição - o que, em tese, poderia ser revelado pela produção intelectual, com destaque para aquela que desemboca em periódicos científicos especializados.

\section{Desenvolvimento regional nos periódicos científicos}

É possível elaborar uma noção mais precisa de desenvolvimento regional, 'a partir de uma aproximação desde a realidade brasileira', tomando os periódicos científicos - isto é, revistas especializadas, que publicam artigos, ensaios e resenhas, impressas ou online (como passou a ser mais comum), com conselhos editoriais e normas bem definidas de publicação - como referência? Talvez, sim. Cabe, no entanto, advertir para algumas dificuldades. A primeira: está se falando de periódicos científicos publicados apenas no Brasil? Ou, também, de publicados em outros países? Se também nestes últimos, então, em quais idiomas? Como se sabe, em geral, incluem-se (por certa "vocação" da academia brasileira de internacionalizar-se, sobretudo, "em inglês") os publicados nos EEUU e no Reino Unido. Mas, como ficam os publicados em outras nações e outros idiomas? A segunda dificuldade: está se falando de periódicos apenas sobre desenvolvimento regional? Ou de periódicos que cobrem, entre diversos temas, também, desenvolvimento regional? É preciso, de qualquer maneira, que tragam desenvolvimento regional - ou desenvolvimento, ou 
regional... - no título e/ou entre as palavras-chave? Se outros periódicos podem ser considerados, então, qual é, por assim dizer, a fronteira tolerável? Poder-se-ia, por exemplo, passar a incluir nessa lista um periódico de biologia que publicasse um artigo de desenvolvimento regional? Ademais das mencionadas, há, evidentemente, inúmeras outras dificuldades, mas que, devido ao espaço exíguo, não podem ser referidas aqui.

De qualquer forma, as dificuldades apontadas acima são reais. Contudo, para contorná-las pode-se - e, dadas as circunstâncias, deve-se - eleger um critério que conta com o reconhecimento dos próprios editores dos periódicos: a sua avaliação, como vem sendo realizada, pela antes já mencionada CAPES. Cabe lembrar, uma vez mais, que essa agência regula a pós-graduação brasileira e, para tanto, considera a qualidade da produção intelectual do pessoal ligado aos PPG (docentes, pósgraduandos...). Tal produção, como se sabe, é publicada na forma de artigos científicos em periódicos indexados. Aqui se parte deste critério - isto é, do fato de que os periódicos que importam passaram por avaliação do chamado "Qualis Periódicos"6 - para se elaborar uma noção mais precisa de desenvolvimento regional a partir de uma aproximação desde a realidade brasileira. Então, tomando em conta o referido critério, tem-se a questão que aqui conta: em quais periódicos (indexados) têm sido publicados artigos científicos que correspondem à produção intelectual em desenvolvimento regional no Brasil?

\section{Quadro 1. Revistas de/sobre desenvolvimento regional cf. Qualis Periódicos/CAPES}

\begin{tabular}{|c|c|c|c|}
\hline Nome do periódico & Responsável pela publicação & Endereço eletrônico & Qualis \\
\hline $\begin{array}{l}\text { Desenvolvimento } \\
\text { em Questão }\end{array}$ & $\begin{array}{l}\text { Programa de Pós-Graduação em } \\
\text { Desenvolvimento / Unijuí }\end{array}$ & $\begin{array}{c}\text { https://www.revistas.unijui.e } \\
\text { du.br/index.php/desenvolvim } \\
\text { entoemquestao/index }\end{array}$ & $\mathrm{B} 2$ \\
\hline $\begin{array}{c}\text { Desenvolvimento } \\
\text { Regional em debate } \\
{[\mathrm{DRd}]}\end{array}$ & $\begin{array}{l}\text { Programa de Mestrado em } \\
\text { Desenvolvimento Regional / } \\
\text { Universidade do Contestado }\end{array}$ & $\begin{array}{l}\text { http://www.periodicos.unc.b } \\
\text { r/index.php/drd }\end{array}$ & B3 \\
\hline $\begin{array}{c}\text { Economía, Sociedad } \\
\text { y Territorio }\end{array}$ & $\begin{array}{c}\text { El Colegio Mexiquense A.C. / } \\
\text { México }\end{array}$ & $\begin{array}{c}\text { https://est.cmq.edu.mx/inde } \\
\text { x.php/est }\end{array}$ & B1 \\
\hline $\begin{array}{c}\text { EURE Revista } \\
\text { Latinoamericana de } \\
\text { Estudios Urbano } \\
\text { Regionales }\end{array}$ & $\begin{array}{c}\text { Instituto de Estudios Urbanos y } \\
\text { Territoriales, Pontificia } \\
\text { Universidad Católica de Chile }\end{array}$ & $\begin{array}{c}\text { http://www.eure.cl/index.ph } \\
\text { p/eure }\end{array}$ & $\mathrm{A} 1$ \\
\hline Informe GEPEC & $\begin{array}{l}\text { Programa de Pós-Graduação em } \\
\text { Desenvolvimento Regional e } \\
\text { Agronegócio / UNIOESTE }\end{array}$ & $\begin{array}{c}\text { http://e- } \\
\text { revista.unioeste.br/index.ph } \\
\text { p/gepec }\end{array}$ & B1 \\
\hline
\end{tabular}

\footnotetext{
${ }^{6}$ Ver

https://sucupira.capes.gov.br/sucupira/public/consultas/coleta/veiculoPublicacaoQualis/listaConsulta GeralPeriodicos.jsf.
} 


\begin{tabular}{|c|c|c|c|}
\hline $\begin{array}{l}\text { Revista Brasileira de } \\
\text { Desenvolvimento } \\
\text { Regional [RBDR] }\end{array}$ & $\begin{array}{l}\text { Programa de Pós-Graduação em } \\
\text { Desenvolvimento Regional / FURB }\end{array}$ & www.furb.br/rbdr & $\mathrm{B} 2$ \\
\hline $\begin{array}{l}\text { Revista Brasileira de } \\
\text { Estudos Urbanos e } \\
\text { Regionais [RBEUR] }\end{array}$ & $\begin{array}{l}\text { Associação Nacional de Pesquisa e } \\
\text { Pós-Graduação em Planejamento } \\
\text { Urbano e Regional [ANPUR] }\end{array}$ & $\begin{array}{c}\text { http://rbeur.anpur.org.br/rbe } \\
\text { ur }\end{array}$ & $\mathrm{A}_{2}$ \\
\hline $\begin{array}{l}\text { Revista Brasileira de } \\
\text { Gestão e } \\
\text { Desenvolvimento } \\
\text { Regional [RBGDR] }\end{array}$ & $\begin{array}{l}\text { Programa de Pós-Graduação } \\
\text { em Gestão e Desenvolvimento } \\
\text { Regional / UNITAU }\end{array}$ & $\begin{array}{l}\text { http://www.rbgdr.net/revista } \\
\text { /index.php/rbgdr }\end{array}$ & $\mathrm{A}_{2}$ \\
\hline $\begin{array}{l}\text { REDES (Santa Cruz } \\
\text { do Sul. Online) }\end{array}$ & $\begin{array}{c}\text { Programa de Pós-Graduação em } \\
\text { Desenvolvimento Regional / } \\
\text { UNISC }\end{array}$ & $\begin{array}{l}\text { https://online.unisc.br/seer/in } \\
\text { dex.php/redes }\end{array}$ & B1 \\
\hline $\begin{array}{l}\text { Revista Política e } \\
\text { Planejamento } \\
\text { Regional [RPPR] }\end{array}$ & $\begin{array}{l}\text { Ministério da Integração Nacional; } \\
\text { Associação Nacional dos Centros } \\
\text { de Pós-Graduação em Economia; } \\
\text { Associação Nacional de Pós- } \\
\text { Graduação e Pesquisa em } \\
\text { Planejamento Urbano e Regional; } \\
\text { Instituto de Pesquisa Econômica } \\
\text { Aplicada }\end{array}$ & $\begin{array}{c}\text { http://www.revistappr.com.b } \\
\text { r }\end{array}$ & B4 \\
\hline $\begin{array}{l}\text { RDE-Revista de } \\
\text { Desenvolvimento } \\
\text { Econômico }\end{array}$ & $\begin{array}{c}\text { Programa de Pós-graduação em } \\
\text { Desenvolvimento Regional e } \\
\text { Urbano / UNIFACS }\end{array}$ & $\begin{array}{l}\text { http://revistas.unifacs.br/inde } \\
\text { x.php/rde }\end{array}$ & B2 \\
\hline $\begin{array}{c}\text { RPD-Revista } \\
\text { Paranaense de } \\
\text { Desenvolvimento }\end{array}$ & $\begin{array}{c}\text { Instituto Paranaense de } \\
\text { Desenvolvimento Econômico e } \\
\text { Social [IPARDES] }\end{array}$ & $\begin{array}{l}\text { http://www.ipardes.pr.gov.b } \\
\text { r/ojs/index.php/revistaparana } \\
\text { ense/index }\end{array}$ & B2 \\
\hline
\end{tabular}

Fonte: Elaboração própria.

A lista acima traz apenas 12 periódicos, dois deles que publicam em espanhol (um do México, outro do Chile), os restantes 10, brasileiros, que publicam em português. Por que, por exemplo, a estadunidense Antipode ou a francesa Confins ou a espanhola Scripta Nova, reconhecidamente, importantes revistas deste (e para este) campo, não estão inclusas? A hipótese é de que investigadores brasileiros, vinculados ou não a grupos de pesquisa, ligados ou não a PPG, tendem a publicar, sobretudo, em periódicos brasileiros, talvez, em periódicos de outros países da América Latina. Voltando à lista: o ponto de partida é que o periódico seja destinatário da produção intelectual sobre desenvolvimento regional de pesquisadores brasileiros. Outro ponto importante é que todos os periódicos que integram a lista têm, pelo menos, cinco anos de existência - ou: cinco volumes publicados. Por fim, outro ponto é que todos devem ter passado pela avaliação do chamado "Qualis Periódicos" da CAPES. Já a razão para elaborar uma lista que contenha apenas 12 periódicos é arbitrária (poder-se-ia fazer uma lista menor ou maior). E a razão para que fossem incluídos exatamente estes 12 periódicos decorre de consulta um pouco mais cuidadosa ao "Qualis Periódicos" da área "Planejamento Urbano e Regional/Demografia". Cumpre registrar que se consideraram os 18 PPG e os três Mestrados Profissionais em Desenvolvimento Regional, tanto para se aferir o destino da produção intelectual de seus docentes quanto para se verificar se algum dos PPG edita alguma revista. 
Em síntese, além dos dois publicados, respectivamente, no México e no Chile, a lista dos 12 periódicos acima inclui sete publicados por PPG da subárea de desenvolvimento regional; entre os outros três, um é publicado pela ANPUR, outro pelo IPARDES e outro conjuntamente pelo Ministério da Integração Nacional e pelo IPEA. Em termos de avaliação, apenas três se encontram no extrato $A$, sendo o melhor avaliado um periódico não brasileiro.

Tomando-se na devida conta o acima exposto, e dado ser esta uma lista mínima inicial, daqui emerge como novo desafio para o campo do desenvolvimento regional a necessidade de precisar melhor a lista, talvez, considerando/acrescentando outros critérios.

\section{Desenvolvimento regional: um novo "campo"?}

Nesta seção se pretende, com base no que se expôs até aqui, explorar a possibilidade de passar a tratar "desenvolvimento regional" como um possível novo campo7. Três breves passos serão dados com vistas a formular uma proposição que convirja com este intento. Primeiramente, será importante recordar as disciplinas de "origem". Recorrendo a uma prosopopeia: de onde têm "falado" os estudos de desenvolvimento regional até aqui? Em segundo lugar, será preciso passar, uma vez mais, pela dicotomia 'conhecimento positivo' e 'conhecimento normativo', agora, desde o ponto de onde se busca formular uma noção de desenvolvimento regional que possa caracterizar um campo. E, por último, sugerir-se-á que, com desenvolvimento regional, se está na presença de uma "teoria de médio alcance", se não um pré-requisito, então, pelo menos, uma condição importante para o reconhecimento de desenvolvimento regional enquanto um campo de maior autonomia.

Primeiro passo: de que disciplinas têm partido os estudos conhecidos de desenvolvimento regional? Cabe lembrar que desenvolvimento regional pressupõe o desenvolvimento de uma região. Por isso, trata-se de perguntar: $\mathrm{O}$ que é região? $\mathrm{O}$ que é desenvolvimento? Sem lugar a dúvidas, as respostas têm sido buscadas, especialmente, na Geografia e na Economia. Contudo, desenvolvimento regional não resulta apenas do que aportam essas duas disciplinas. Evidentemente, não é o caso de insistir em contatos com o que é estranho ou distante, nem tampouco de forçar interfaces com "Planejamento Urbano e Regional” - isto é, com a área na qual está contida a subárea de desenvolvimento regional quando se lida com a pós-graduação. Aliás, cumpre lembrar que tanto Economia quanto Geografia constituem "áreas" autônomas na classificação da CAPES. Então, e voltando ao ponto, o que aqui se

\footnotetext{
7 Aqui se entendendo por campo um espaço que dispõe de alguma autonomia, portanto, que é governado a partir de normas e regras próprias. Apesar disso, um campo não pode ser dissociado de seu entorno, pelo qual é, em menor ou maior grau, condicionado. Internamente, um campo implica conflito entre os "agentes" que o integram, visando a conquista ou a preservação de posições. Hierarquias se estabelecem (e se desfazem) em conformidade com o "capital" detido por cada agente do respectivo campo. Compromissos celebrados entre os agentes podem aplacar conflitos e assegurar, temporariamente, alguma estabilidade ao campo. Mas, se, por um lado, tensões internas podem ser contidas, por outro, ameaças oriundas do entorno também podem gerar insegurança. Se, como parece evidente, o entendimento de campo sugere constante movimento, então essa noção possui um caráter inequivocamente relacional (BOURDIEU, 2004).
} 
designa como desenvolvimento regional também se nutre de outras fontes, com destaque para a Sociologia, a Ciência Política, a Antropologia ${ }^{8}$, a História e, eventualmente, o Direito e a Arquitetura. De forma que, ao invés de limitar as vozes do que seja desenvolvimento regional ao que emana de uma ou duas disciplinas, pode-se (e deve-se) mobilizar outros campos de conhecimento, já que - e este passa a ser um pressuposto daqui por diante - desenvolvimento regional tem assumido, talvez, mais destacadamente no âmbito dos PPG, um nítido caráter interdisciplinar 9. Assim, outro desafio que se apresenta para os estudos do desenvolvimento regional consiste em inventariar a produção intelectual sobre desenvolvimento regional que tem origem não apenas na Economia e na Geografia (mais ou menos conhecida), mas, sobretudo, nas outras disciplinas acima referidas (mais ou menos desconhecida).

Segundo passo: no que se refere à dicotomia 'conhecimento positivo' e 'conhecimento normativo', é preciso reconhecer que ela não apenas está devidamente disseminada, mas também que parece suficientemente didática para indicar diferenças entre o que existe e o que se deseja que exista. Entretanto, a distinção entre o fato objetivo e concreto - que, em tese, corresponde à realidade tal como ela supostamente é - e a manifestação idealizada subjetiva - que indica como a realidade deveria ser - é, na verdade, inadequada para se diferenciar desenvolvimento regional enquanto dado empírico e enquanto propósito conscientemente delineado. A inadequação dessa distinção repousa em algumas dificuldades. Talvez a mais importante seja que a "realidade tal como ela supostamente é" não se distingue, assim, sem mais, da "realidade tal como ela deveria ser". Porque fato concreto e propósito delineado estão imbricados ${ }^{10}$. Afinal, a realidade é dinâmica. A distinção entre uma dimensão positiva e uma dimensão normativa, como postulada pelo positivismo, é, em geral, arbitrária. E o caso do desenvolvimento regional não foge à regra. Dessa dificuldade decorre outra: a rigor, se houvesse desenvolvimento regional - seja lá o que isso signifique -, então, não existiria razão para se intervir na realidade, para se moldar essa realidade, enfim, para fazê-la tornar-se aquilo que ela deveria ser. De maneira que o fato consumado do desenvolvimento regional dispensaria a formulação de uma política de desenvolvimento regional. Daí se infere que a distinção é inadequada se a intenção do desenvolvimento regional se justifica apenas em face de um fato como a inexistência (ou melhor: o não-fato) de desenvolvimento regional. O fato contra o qual se posiciona qualquer intenção (uma "política") de desenvolvimento regional terá, pois, que ser a falta de desenvolvimento regional - falta que pode ser traduzida,

\footnotetext{
${ }^{8}$ Apenas para exemplificar, pode-se formular uma "acepção" ancorada na Antropologia segundo a qual "é a história que faz uma região [...] seus múltiplos planos não se encaixam em limites geográficos [...] A questão torna-se mais complexa quando [se indaga] de que história [se está] falando. Quem são seus protagonistas? Quais [são] as categorias discursivas acionadas? Como as narrativas de experiências são acionadas, contadas e recontadas? Quais [são] as categorias silenciadas?" (RENCK, 2004, p. 12).

9 Aliás, dependendo do sentido que se lhe conferir, parece pertinente reconhecer à expressão "desenvolvimento regional" também um caráter pluridisciplinar, multidisciplinar ou transdisciplinar (MATTEDI; THEIS, 2002).

${ }^{10}$ De minha parte, simpatizo com a ideia de que "o objetivo não é compreender a realidade [como ela é], mas compreender [...] suas contradições como parte da luta para mudar o mundo" (HOLLOWAY, 2003, p. 177).
} 
por exemplo, por disparidades regionais. Assim, o fato da existência de desigualdades (sociais, econômicas, políticas...) entre regiões é o que convidaria a agir em favor de desenvolvimento regional, vale dizer, de uma redução nas disparidades regionais.

Terceiro passo: desenvolvimento regional é uma teoria? Ou não passa de uma hipótese? Na realidade desenvolvimento regional não é nem uma simples hipótese nem uma consistente teoria. É algo que se situa entre a hipótese e a teoria. Não sendo nem hipótese nem teoria, sugere-se que desenvolvimento regional seja uma teoria de médio alcance. Teorias desse tipo são:

teorias intermediárias entre as pequenas, mas hipóteses necessárias de trabalho que surgem [...] durante a rotina das pesquisas diárias e os amplos esforços sistemáticos para desenvolver uma teoria unificada capaz de explicar todas as uniformidades observadas de comportamento, organização e mudança sociais (Merton, 1970, p. 51).

Essa modalidade de teorias, não sendo nem pequenas e insignificantes hipóteses nem grandes e consistentes teorias (como, por exemplo, os sistemas teóricos da economia, da sociologia etc.), é utilizada, sobretudo, como uma espécie de guia para investigações empíricas, ocupando:

\footnotetext{
uma situação intermediária entre as teorias gerais de sistemas sociais, as quais estão muito afastadas das espécies particulares de comportamento, organização e mudança sociais para explicar o que é observado, e as minuciosas ordenadas descrições de pormenores que não estão de modo algum generalizados (Merton, 1970, p. 51).
}

Abstrações também podem estar presentes em "teorias de médio alcance". No entanto, estas se encontram bem mais próximas da realidade social em questão, de maneira que possam ser testadas empiricamente. Assim, as teorias de médio alcance, como se sugere no caso do desenvolvimento regional, por envolverem aspectos limitados da realidade social, não poderiam confundir-se com grandes teorias, não obstante sejam mais que simples hipóteses (Merton, 1970, p. 51).

Dados os passos anunciados no início desta seção - isto é, a constatação de que desenvolvimento regional não deve ser limitado ao que emana de uma ou duas disciplinas, na medida em que, devido ao seu evidente caráter interdisciplinar, tende a se articular com outros campos de conhecimento; a consideração de que a distinção entre fato objetivo e concreto e manifestação idealizada subjetiva é inadequada para se diferenciar desenvolvimento regional como dado empírico, de um lado, e propósito delineado, de outro; e, a sugestão de que com desenvolvimento regional se esteja na presença de uma "teoria de médio alcance" - talvez estejam atendidas condições importantes para a formulação de uma proposição que contribua para o reconhecimento de desenvolvimento regional enquanto campo de maior autonomia.

$\mathrm{Na}$ expectativa de que essas condições estejam, de fato, atendidas, pode-se enfrentar a questão-chave: o que é desenvolvimento regional desde a perspectiva sociocultural brasileira? Como ponto de partida pode-se tomar a acima referida inadequação da distinção entre fato e intenção. Desenvolvimento regional é algo bom que não existe, em favor do que dever-se-iam mobilizar energias, em resposta a algo ruim que existe, isto é, desigualdades (sociais, econômicas, políticas...) entre 
regiões, as disparidades regionais. De que resultam mesmo essas disparidades regionais? Numa economia capitalista, o desenvolvimento das forças produtivas sobre dado território produz desigualdades, sobretudo, porque, em cada região, a provisão de meios de produção é, quantitativa e qualitativamente, diferenciada, assim como é diferenciada a produtividade de sua força de trabalho. Uma vez atuando a força de trabalho sobre os recursos produtivos mobilizados para a produção de mercadorias em cada região, no âmbito de dada formação nacional, o território será progressivamente alterado - de “meio natural” ele, progressivamente, se converte em "meio técnico-científico-informacional" (SANTOS; SILVEIRA, 2013). Essa divisão territorial do trabalho evoluirá para a coexistência de coordenação entre algumas grandes metrópoles, numerosas cidades médias, muitos pequenos centros urbanos - em que se desenvolverão atividades industriais e de serviços - e o espaço rural - em que, com cada vez maior auxílio da indústria, desenvolver-se-ão atividades primárias (agricultura, pecuária, mineração etc.). Essa divisão sócio-espacial do trabalho configura uma paisagem em permanente modificação, marcada pela produção contínua de desigualdades.

Desenvolvimento regional é algo bom com que se procura combater algo ruim (as desigualdades). No entanto, não existe apenas um remédio para as disparidades regionais. Não parece despropositado notar que a expressão "desenvolvimento regional” já sugere uma divergência em relação às desigualdades: é preferível desenvolvimento regional a disparidades regionais. Todavia, o que parece fundamental é que tem se mobilizado, pelo menos, três estratégias para se enfrentar as disparidades regionais (com suas respectivas implicações teóricas e políticas) - o que remete a um debate travado no âmbito da Geografia Econômica: para um primeiro enfoque, desigualdades só podem ser corrigidas pelo mercado; para outro, desigualdades só podem ser corrigidas pelo Estado; e, para o terceiro, desigualdades deveriam/poderiam ser evitadas pela superação das condições materiais que, continuamente, as recriam.

O primeiro enfoque recomenda deixar que o mercado se autorregule, sem intervenção, seja de grupos organizados da sociedade (os trabalhadores, através de sindicatos...), seja do Estado. Para os seus advogados, as desigualdades resultam de/são agravadas, precisamente, por demasiada intervenção estatal. A despeito de reconhecer a hegemonia dos liberais no debate, investir num detalhamento de seu argumento constituiria desperdício de tempo e papel escassos.

O segundo enfoque propõe a intervenção do Estado. O diagnóstico é de que o mercado autorregulado é uma ficção; deixando-se que funcione sem coordenação, inevitavelmente, produzirá desigualdades. Portanto, há dois pontos a considerar: é preciso (a) corrigir as desigualdades e (b) regular o mercado que as produz. Começando por este último, o Estado deve regular o mercado que gera desigualdades, por exemplo, por meio de leis etc. Assim, a presença do Estado, este agente incumbido de coordenar o mercado, atenuaria a geração de desigualdades sócio-espaciais. Já com relação às desigualdades diagnosticadas, para elas têm sido sugeridas - e, de fato, elas têm sido enfrentadas por - medidas ou políticas baseadas no crescimento econômico das regiões "perdedoras", com vistas a nivelá-las com as regiões "ganhadoras". Não é difícil perceber, aqui, uma indicação para andar em círculos: os meios com que se sugere combater o mal são os mesmos que o provocam; ou, dito com todas as letras: as desigualdades inter-regionais 
diagnosticadas, resultantes de um crescimento econômico desigual, são, supostamente, melhor combatidas com... mais crescimento econômico - talvez, assegurando às regiões "perdedoras" taxas mais elevadas?! Um problema adicional se apresenta para os intervencionistas: empiricamente, as desigualdades estão por toda parte, crescendo por toda parte, apesar de se encontrar o Estado por toda parte. De maneira que a presença do Estado, ao invés de favorecer o enfrentamento das desigualdades, talvez tenha se tornado funcional à sua existência e continuidade.

O terceiro enfoque elege a autonomia de cada comunidade regional na definição de seu projeto societário. Aqui não se desconhece nem o mercado nem o Estado, nem tampouco se ignora a existência da moderna sociedade produtora de mercadorias, da qual o mercado e o Estado são instituições ancilares. Mas, precisamente por isso, o remédio mais indicado para combater as desigualdades sócio-espaciais não poderia cingir-se às medidas postuladas pelos dois enfoques anteriores. O diagnóstico, aliás, é outro: mantida intacta a moderna sociedade produtora de mercadorias, com sua base produtiva e correspondente superestrutura, dado que aí incidem todos os efeitos do desenvolvimento geográfico desigual (THEIS, 2009; THEIS; BUTZKE, 2012), as disparidades inter-regionais tendem a se reproduzir continuamente. Logo, será inócua a espera passiva pela ação do Estado, por meio de políticas de desenvolvimento regional, para que se atenuem ou mesmo extingam as desigualdades sócio-espaciais. As desigualdades poderão ser extintas se os membros das comunidades regionais resistirem ativamente à permanente coacção do capital para que sejam destituídos do controle de seus meios de vida; sendo assalariados, se também ativamente reconquistarem os meios com os quais podem prover-se a si e aos seus das condições materiais e espirituais para uma vida digna. Em síntese: as desigualdades poderão ser extintas se os membros das comunidades regionais recuperarem sua autonomia (BÖHM; DINERSTEIN; SPICER, 2010; DINERSTEIN, 2013). Em uma formação social periférica e dependente (em relação às formações sociais que vêm comandando a economia-mundo) como a brasileira, é a utopia concreta $(B L O C H, 2005)$ com que se pode formular uma noção de desenvolvimento regional.

\section{Considerações finais}

Este artigo foi dedicado à problemática do desenvolvimento regional. Entretanto, o que, realmente, se buscou fazer era oferecer uma compreensão um pouco mais contextualizada do que pudesse ser desenvolvimento regional. É preciso reconhecer que tem havido tentativas visando precisar melhor o que se pode entender por desenvolvimento regional. Todavia, em contraste com os esforços realizados até agora, procurou-se definir minimamente o contexto no qual se pudesse formular uma noção mais precisa de desenvolvimento regional. De maneira que a preocupação maior foi com o quadro no qual se poderia elaborar uma compreensão de desenvolvimento regional. Tal quadro, como se informou na introdução, tomaria o Brasil como lócus privilegiado e suas características socioculturais como referências inamovíveis.

A que resultados se chegou? Em primeiro lugar, o breve panorama internacional esboçado logo na segunda seção permitiu que se verificasse que a problemática do desenvolvimento regional também recebe atenção em outros 
países. E o que se entende por essa expressão "fora do Brasil"? Embora outras preocupações possam ser identificadas (desigualdades sócio-espaciais, relações de poder, aspectos éticos, questões metodológicas etc.), predomina a compreensão de desenvolvimento regional como um processo essencialmente econômico.

Em segundo lugar, como se viu, a figura de Celso Furtado logo se destaca entre os numerosos estudiosos da questão regional no Brasil. Com efeito, o economista paraibano identificou e analisou com rara competência a problemática regional, desvendando a natureza do processo de desenvolvimento desigual que preside a economia brasileira, subdesenvolvida e periférica, e privilegiando a política como meio para desmontar os mecanismos que têm perpetuado as disparidades inter-regionais no Brasil. Por isso, sua obra vem influenciando estudos mais recentes de/sobre desenvolvimento regional como, provavelmente, nenhuma outra.

Em terceiro lugar, nas últimas três décadas, a problemática regional tem sido examinada no Brasil, sobretudo, no ambiente das IES, em especial, no âmbito dos programas de pós-graduação. Como se procurou mostrar, os PPG vêm sendo, de fato, os principais responsáveis pela produção intelectual que tem tido lugar na universidade brasileira. A atuação dos grupos de pesquisa e dos próprios pesquisadores tem inegável relevância neste contexto. Mas, deve ter ficado evidente, sobretudo, que já não se pode falar de desenvolvimento regional sem fazer referência à pós-graduação no Brasil.

Em quarto lugar, isso é bastante perceptível quando se busca verificar o destino da produção intelectual em/sobre desenvolvimento regional. É óbvio que não se poderia fazer aqui um inventário exaustivo dos periódicos científicos. Contudo, a aproximação realizada permitiu que se caracterizasse o conjunto de revistas especializadas em desenvolvimento regional nas quais vem desaguando a produção intelectual brasileira. Não há dúvida, porém, que - por razões que não cabe explorar neste ponto - periódicos de desenvolvimento regional têm sido, comparativamente, menos bem avaliados.

Em quinto e último lugar, pode-se avançar em direção à formulação de uma proposição mais concreta, mas, não sem antes considerar que desenvolvimento regional não deve ser limitado ao que aporta $(m)$ uma ou duas disciplinas, dado o seu caráter interdisciplinar; a distinção entre fato objetivo/concreto e manifestação idealizada/subjetiva é inadequada para diferenciar desenvolvimento regional como dado empírico de propósito delineado; e, com desenvolvimento regional se está na presença não de uma pequena hipótese ou de uma grande teoria, mas de uma "teoria de médio alcance". Dados esses passos, distinguiu-se entre três enfoques na formulação de uma proposição mais concreta de desenvolvimento regional. E esse quadro que se acaba de esboçar talvez atenda às exigências envolvidas com o reconhecimento de um campo de conhecimento. Daqui em diante se abrem possibilidades variadas para se elaborar uma noção um pouco mais precisa e, ao mesmo tempo, mais utópica de desenvolvimento regional - 'a partir de uma aproximação desde a realidade sociocultural brasileira', que passe a dar alguma visibilidade e levar na devida conta o seu passado colonial, o sofrimento dos povos originários e das populações compulsoriamente transplantadas, a presença das mulheres, a diversidade da natureza. 


\section{REFERÊNCIAS}

BANDEIRA, Pedro. Participação, articulação de atores sociais e desenvolvimento regional (= Texto para Discussão, N. 630). Brasília: IPEA, 1999.

BANDEIRA, Pedro Silveira. Diferenças Regionais Quanto ao Capital Social e Crescimento Econômico no Rio Grande do Sul. Redes (Santa Cruz do Sul. Online), Santa Cruz do Sul, v. 12, n. 1, p. 93-124, nov. 2007. ISSN 1982-6745. Disponível em: https://online.unisc.br/seer/index.php/redes/article/view/98. Acesso em: mai. 2019. doi:https://doi.org/10.17058/redes.v12i1.98.

BELHEDI, Amor. La fracture territoriale: la dimension spatiale de la révolution tunisienne. Tunis: Wassiti Editions, 2012.

BERCOVICI, Gilberto. Desigualdades regionais, Estado e constituição. São Paulo: Max Limonad, 2003.

BLOCH, Ernst. O princípio esperança I. Trad. Nélio Schneider. Rio de Janeiro: Ed. UERJ; Contraponto, 2005.

BÖHM, Steffen; DINERSTEIN, Ana C.; SPICER, André. (Im)possibilities of Autonomy: Social Movements in and beyond Capital, the State and Development. Social Movement Studies, 9 (1), p. 17-32, 2010.

BOURDIEU, Pierre. Os usos sociais da ciência: por uma sociologia clínica do campo científico. São Paulo: UNESP, 2004.

CANO, Wilson. Desequilíbrios regionais e concentração industrial no Brasil, 19301995. Campinas: Unicamp/IE, 1998 [1981].

CARLEIAL, Liana M. F. A questão regional no Brasil contemporâneo. In: LEVINAS, L.; CARLEIAL, L. M. F.; NABUCO, M. R. (org.) Reestruturação do espaço urbano e regional no Brasil. São Paulo: Ed. Hucitec; Annablume, p. 35-58, 1993.

CARLEIAL, Liana M. F. O desenvolvimento regional brasileiro ainda em questão. Revista Política e Planejamento Regional, 1 (1), p. 1-21, 2014.

CARVALHO, Otamar de. Desenvolvimento regional: um problema político. Campina Grande: EDUEPB, 2014.

CIRANI, Claudia Brito Silva; CAMPANARIO, Milton de Abreu; MARQUES DA SILVA, Heloisa Helena. A evolução do ensino da pós-graduação senso estrito no Brasil: análise exploratória e proposições para pesquisa. Avaliação, 20 (1), p. 163-187, 2015.

COY, Martin. Regionalentwicklung in Rondônia (Brasilien): integrierte ländliche Entwicklung und politische Rahmenbedingungen. Geographische Zeitschrift, 74 (3), p. 177-185, 1986. 
DAWKINS, Casey J. Regional development theory: conceptual foundations, classic works, and recent developments. Journal of Planning Literature, 18, (2), p. 131-172, 2003.

DINERSTEIN, Ana Cecilia. “La autonomía y sus imaginarios prácticos en permanente construcción". In: DINERSTEIN, Ana Cecilia [et al.] (org.) Movimientos sociales y autonomía colectiva: la política de la esperanza en América Latina. Buenos Aires, Capital Intelectual, p. 23-38, 2013.

DINIZ, Clélio Campolina. Celso Furtado e o desenvolvimento regional. Nova Economia, 19 (2), p. 227-249, 2009.

FERNÁNDEZ, Victor Ramiro. Estrategia(s) de desarrollo regional bajo el nuevo escenario global-local: revisión crítica sobre su(s) potencialidad(es) y limites. Revista EURE, 28 (82), p. 43-63, 2001.

FREYRE, Gilberto. Sobre o "manifesto regionalista” de 1926. In: COHN, Sergio. Gilberto Freyre (= col. Encontros). Rio de Janeiro: Beco do Azougue, p. 62-97, 2010.

FURTADO, Celso. Intra-country discontinuities: toward a theory of spatial structures. Social Science Information, 6 (6), p. 7-16, 1967.

FURTADO, Celso. Formação econômica do Brasil. 15 ed. São Paulo: Nacional, 1977. FURTADO, Celso. O Brasil pós-“milagre”. 4 ed. Rio de Janeiro: Paz e Terra, 1981. FURTADO, Celso. Análise do "modelo" brasileiro. 7 ed. Rio de Janeiro: Civilização Brasileira, 1982a.

FURTADO, Celso. A nova dependência: dívida externa e monetarismo. Rio de Janeiro: 4 ed. Paz e Terra, 1982b.

FURTADO, Celso. O longo amanhecer: reflexões sobre a formação do Brasil. Rio de Janeiro: Paz e Terra, 1999.

FURTADO, Celso. Perspectivas da economia brasileira. Rio de Janeiro: Centro Internacional Celso Furtado de Políticas para o Desenvolvimento, 2012 [1958].

HIRSCHMAN, Albert O. The strategy of economic development. New Haven: Yale University Press, 1958.

HOLLOWAY, John. Mudar o mundo sem tomar o poder: o significado da revolução hoje. Trad. E. Sader. São Paulo: Viramundo, 2003.

MATTEDI, Marcos A.; THEIS, Ivo M. Cruzando fronteiras: conhecimento e interdisciplinaridade na pesquisa em desenvolvimento regional. Redes (Santa Cruz 
do Sul. Online), Santa Cruz do Sul, v. 7, n. 2, p. 77-94, set. 2017. ISSN 1982-6745. Disponível em: https://online.unisc.br/seer/index.php/redes/article/view/10887 . Acesso em: mai. 2019. doi:https://doi.org/10.17058/redes.v7i2.10887.

MERTON, R. K. Sociologia: teoria e estrutura. Trad. M. Maillet. São Paulo: Mestre Jou, 1970.

MOULAERT, Frank; JESSOP, Bob; MEHMOOD, Abid. Agency, structure, institutions, discourse (ASID) in urban and regional development. International Journal of Urban Sciences, 20 (2), p. 167-187, 2016.

MÜHLINGHAUS, Sabine. Eigenständige Regionalentwicklung als Strategie für periphere ländliche Räume? Eine Untersuchung aus dem Schweizer Berggebiet. Geographica Helvetica, 57 (2), p. 127-134, 2002.

MYRDAL, Gunnar. Economic theory and underdeveloped regions. London: Duckworth, 1957.

OLIVEIRA, Francisco de. Elegia para uma re(li)gião: Sudene, Nordeste, planejamento e conflito de classes. 3 ed. Rio de Janeiro: Paz e Terra, 1981.

PERRIN, J. C. Le développement régional: schémas d'analyse de l'économiste. Cahiers Orstom (Sci. Hum.), 4 (2), p. 7-60, 1967.

PERROUX, François. Economic space: theory and applications. Quarterly Journal of Economics, 64 (1), p. 89-104, 1950.

PERROUX, François. Note sur la notion de póle de croissance. Économie Appliquée, N. 8, p. 307-320, 1955.

RENCK, Arlene. Narrativas da diferença. Chapecó: Argos, 2004.

SANTOS, Milton; SILVEIRA, Maria Laura. O Brasil: território e sociedade no início do século XXI. 17 ed. Rio de Janeiro; São Paulo: Record, 2013.

TAVARES, Hermes Magalhães. Desenvolvimento, região e poder regional: a visão de Celso Furtado. Revista Brasileira de Estudos Urbanos e Regionais, 13 (2), p. 11-26, 2011.

THEIS, Ivo M. Do desenvolvimento desigual e combinado ao desenvolvimento geográfico desigual. Novos Cadernos NAEA, v. 12, n. 2, p. 241-252, dez. 2009.

THEIS, Ivo Marcos; BUTZKE, Luciana. O paradoxo da geografia no capitalismo mundializado: revisitando a lei do desenvolvimento desigual e combinado. In: GALVÃO, Andreia et al. (org.) Capitalismo: crises e resistências. São Paulo: Outras Expressões, p. 83-110, 2012. 
VELASCO, Andrés Enrique Miguel; MALDONADO CRUZ, Pedro; TORRES VALDEZ, Julio César. Desigualdad del desarrollo regional en México. Problemas del

Desarrollo: Revista Latinoamericana de Economía, 38 (151), p. 87-102, 2007.

Ivo Marcos Theis. Economista, doutorado em Geografia (Universität Tübingen/Alemanha), pós-doutorados em Política Científica e Tecnológica (Unicamp) e Desenvolvimento Regional (Unisc), bolsista de Produtividade em Pesquisa 2 do CNPq. Rua Antônio da Veiga, 140, Victor Konder. 89012-900 Blumenau, SC - Brasil - Caixa-postal: 1507. theis@furb.br

Como citar: THEIS, Ivo Marcos. O que é desenvolvimento regional? Uma aproximação a partir da realidade brasileira. Redes, Santa Cruz do Sul, v. 24, n. 3, p. 334-360, set. 2019. ISSN 1982-6745. Disponível em: https://doi.org/10.17058/redes.v24i3.13670 